\title{
Prediction of left ventricular pressure in infants with aortic stenosis ${ }^{\star}$
}

\author{
JOEL I BRENNER, KATHLEEN R BAKER, MICHAEL A BERMAN \\ From the Division of Pediatric Cardiology, University of Maryland Medical School, \\ Baltimore, Maryland, USA
}

SUMmaRY Peak systolic left ventricular pressure was predicted in five infants with aortic stenosis by use of a wall stress constant, $\mathrm{K}$. $\mathrm{K}$ was determined in 10 normal infants according to the formula $\mathrm{K}=\mathrm{P}$. Ds/Ws, where $\mathbf{P}=$ arterial pressure by Doppler, $\mathrm{Ds}=$ end-systolic $\mathrm{LV}$ dimension, and Ws = end-systolic wall thickness. Left ventricular peak systolic pressure was estimated in five infants using the formula $P=K$. Ws/Ds. Excellent correlation was obtained between measured left ventricular pressure and left ventricular-aortic pressure difference at cardiac catheterisation and echo estimates. Echocardiographic assessment of the severity of aortic stenosis may be applied to infants with good results.

Determination of the severity of left ventricular outflow tract obstruction by single crystal echocardiography was first reported by Bennett et al. in adult patients with valvular aortic stenosis. ${ }^{1}$ The peak systolic left ventricular pressure and peak systolic pressure difference across the valve were predicted using relative wall thickness times a constant as an index of left ventricular systolic wall stress. The validity of this wall stress index was based on the observation that, given normal left ventricular function, the magnitude of concentric ventricular hypertrophy increases in response to increased afterload until wall stress is normalised.

The reproducibility and reliability of the wall stress index were subsequently confirmed in children by several investigators. ${ }^{2-5}$ To date, however, these measurements have not been applied to infants under 1 year of age with valvular aortic stenosis. This report communicates our experience with the wall stress index in this age group.

\section{Subjects and methods}

Data were obtained from 15 subjects less than 1 year of age. Informed consent was obtained from the parents/guardians of each infant. Group 1 (control subjects) consisted of 10 infants aged 1 to 11 months, without evidence of cardiopulmonary disease, who underwent echocardiographic examina-

* Presented in part at the Southern Society for Clinical Pediatric Research, New Orleans, Louisiana, January 1978.

Received for publication 2 January 1980 tion during well-baby visits or while in hospital for minor surgical procedures. The constant, $K$, was derived from this group.

Group 2 (aortic stenosis patients) consisted of five infants, aged 2 weeks to 11 months, with valvular aortic stenosis confirmed by complete right and left heart catheterisation. All infants in group 2 had prominent left ventricular forces for age on scalar electrocardiogram. Two infants (cases 2 and 3 ) were in congestive heart failure as manifested by tachypnoea and poor feeding.

Cardiac catheterisation was performed without premedication. Simultaneous left ventricular and descending aortic pressure was measured in four infants and Doppler left brachial pressure in the fifth. The peak left ventricular pressure ranged from 100 to $210 \mathrm{mmHg}$, and the peak pressure difference across the valve ranged from 10 to $110 \mathrm{mmHg}$. The two infants in congestive heart failure were shown to have left-to-right atrial level shunts, left atrial, and pulmonary artery hypertension (mean left atrial pressure 12 and $13 \mathrm{mmHg}$; mean pulmonary artery pressure 55 and $25 \mathrm{mmHg}$, respectively). There were no associated cardiac defects. Three patients required surgical intervention, with two survivors.

Echocardiographic assessments were performed with a Smith-Kline Ekoline 20 ultrasonoscope and a Smith-Kline strip chart recorder using lightsensitive paper. A $5 \mathrm{MHz}$ non-focused transducer was used. The examination was carried out, with the infant supine, and with the transducer in the 
third or fourth intercostal space along the left sternal border, and angled inferiorly and laterally until the posterior mitral valve apparatus was located. A technically adequate study required sweeping the left ventricle from the aorta to the apex, thus allowing visualisation and measurement of the left ventricular dimensions at the free edge of the mitral leaflet.

Measurements of end-diastolic wall thickness (Wd), end-systolic wall thickness (Ws), enddiastolic cavity dimensions (Dd), and end-systolic cavity dimensions (Ds), were made from the echocardiographic trace (Fig. 1). Wall thickness was measured from the endocardium to the epicardium at end-diastole, corresponding to the $Q$ wave of the simultaneous electrocardiogram; and at end-systole, the point of maximal anterior

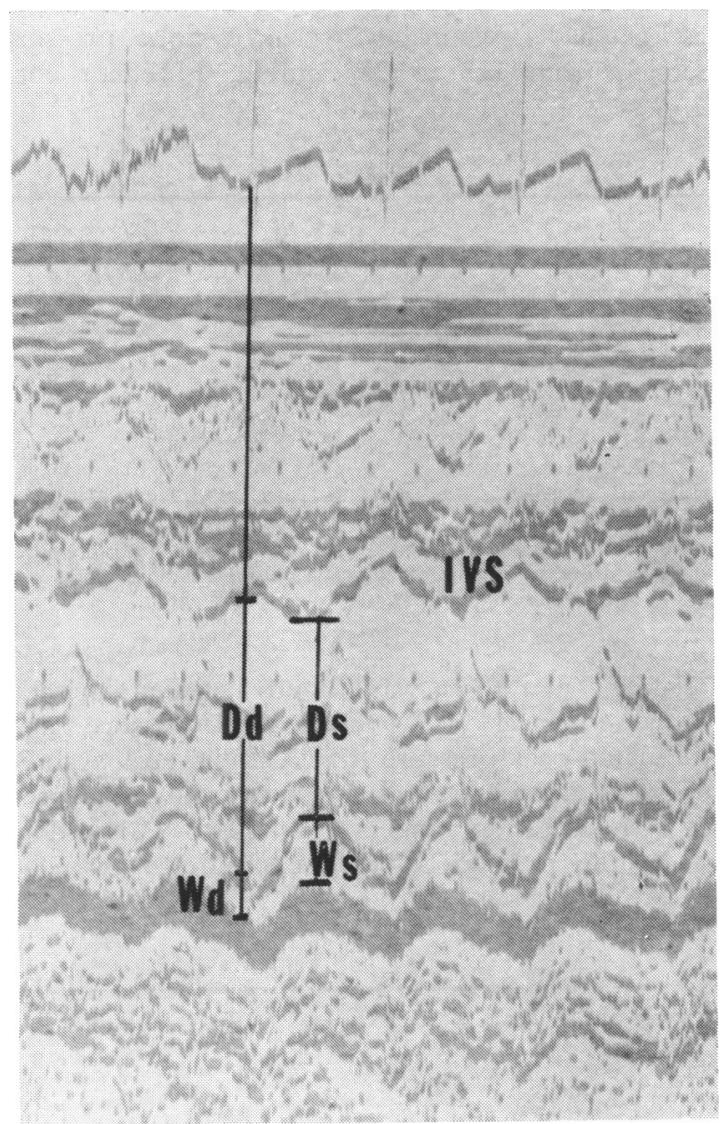

Fig. 1 Representative echocardiogram from a normal infant showing the location of the sites for measurement of left ventricular cavity diastolic dimension ( $D d)$, systolic dimension (Ds), end-diastolic wall thickness (Wd), and end-systolic wall thickness (Ws). IVS, intraventricular septum. motion of the left ventricular posterior wall. Transverse left ventricular end-diastolic and endsystolic cavity dimensions were measured from the endocardial septal echo to the endocardial free wall echo at the $Q$ wave of the electrocardiogram, and at the maximal anterior free wall excursion, respectively.

Peak systolic blood pressure was measured at the time of the echocardiographic examination in each infant, using a Doppler system. The method of Bennett $e t$ al. was then used to derive a pressure constant $(\mathrm{K})$ from the subjects in group $1: \mathrm{K}=\mathrm{P}$. $\mathrm{Ds} / \mathrm{Ws}$, where peak systolic blood pressure was assumed to equal left ventricular pressure in normal controls.

The constant derived from group 1 ( $\mathrm{K}$ in $\mathrm{mmHg}$ ) was then used to estimate peak left ventricular pressure in the patients with aortic stenosis, where $\mathbf{P}=\mathrm{K}$. Ws/Ds. The peak systolic pressure difference was determined by subtracting the Doppler systolic pressure from predicted left ventricular peak systolic pressure by echo. In group 2 , the results were compared with those found at catheterisation.

\section{Results}

The echocardiographic measurements for group 1 are shown in Table 1. End-diastolic wall thickness, end-systolic wall thickness, end-diastolic cavity dimensions, and end-systolic cavity dimensions were all within normal limits. Relative wall thickness (Ws/Ds) ranged from 0.29 to 0.52 (mean \pm a standard deviation of $0.4 \pm 0.07$ ). The percentage of wall thickening with systole ranged from 48 to 114 per cent (mean $72.5 \pm 19.0 \%$ ). Shortening fraction ranged from 27 to 42 per cent (mean $34 \pm 4 \cdot 9 \%$ ). Peak systolic blood pressure by Doppler was 68 to $104 \mathrm{mmHg}$ (mean $86.7 \pm 11.9$ $\mathrm{mmHg}$ ). The derived pressure constant, $\mathrm{K}$, from this group ranged from 183 to $265 \mathrm{mmHg}$ (mean $216.7 \pm 21.9 \mathrm{mmHg}$ ).

The echocardiographic data from the aortic stenosis patients (group 2) are shown in Table 2, and the data are compared in Table 3. Enddiastolic wall thickness ranged from 0.42 to $0.64 \mathrm{~cm}$ (mean $0.51 \pm 0.08 \mathrm{~cm}$ ), and end-systolic wall thickness ranged from 0.70 to $1.17 \mathrm{~cm}(0.93 \pm 0.21 \mathrm{~cm})$. Both measurements were significantly greater than those in the control group ( $<<0.01)$. End-diastolic cavity dimension and end-systolic cavity dimension did not vary significantly from group 1 ( $p>0.5$, and $p>0.2$, respectively). Relative wall thickness was greater in group 2, with a range of 0.56 to $1.03 \mathrm{~cm}$ (mean $0.75 \pm 0.19 \mathrm{~cm}$ ). Percentage wall thickening ranged from 32 to 140 per cent (mean $83.4 \pm 41 \%$ ), 
Table 1 Control group

\begin{tabular}{|c|c|c|c|c|c|c|c|c|c|c|c|}
\hline Case no. & Age & $\begin{array}{l}\text { Weight } \\
\text { (kg) }\end{array}$ & $\begin{array}{l}W d \\
(\mathrm{~cm})\end{array}$ & $\begin{array}{l}W s \\
(\mathrm{~cm})\end{array}$ & $\begin{array}{l}D d \\
(\mathrm{~cm})\end{array}$ & $\begin{array}{l}D s \\
(\mathrm{~cm})\end{array}$ & $W s / D s$ & $\% W T$ & $\% S F$ & $\begin{array}{l}B P s \\
(m m H g)\end{array}$ & $\begin{array}{l}K \\
(m m H g)\end{array}$ \\
\hline $\begin{array}{r}1 \\
2 \\
3 \\
4 \\
5 \\
6 \\
7 \\
8 \\
9 \\
10\end{array}$ & $\begin{array}{l}11 \mathrm{mth} \\
6 \mathrm{wk} \\
2 \mathrm{mth} \\
2 \mathrm{mth} \\
2 \mathrm{mth} \\
4 \mathrm{mth} \\
2 \mathrm{mth} \\
1 \mathrm{mth} \\
6 \mathrm{mth} \\
2 \mathrm{mth}\end{array}$ & $\begin{array}{r}10 \cdot 5 \\
4 \cdot 3 \\
4 \cdot 5 \\
4 \cdot 2 \\
4 \cdot 6 \\
5 \cdot 3 \\
4 \cdot 8 \\
3 \cdot 6 \\
6 \cdot 4 \\
4 \cdot 0\end{array}$ & $\begin{array}{l}0.40 \\
0.31 \\
0.35 \\
0.35 \\
0.30 \\
0.35 \\
0.34 \\
0.24 \\
0.41 \\
0.22\end{array}$ & $\begin{array}{l}0.67 \\
0.60 \\
0.60 \\
0.55 \\
0.50 \\
0.55 \\
0.65 \\
0.41 \\
0.75 \\
0.47\end{array}$ & $\begin{array}{l}2 \cdot 80 \\
2 \cdot 10 \\
1 \cdot 90 \\
2 \cdot 10 \\
2 \cdot 15 \\
2 \cdot 10 \\
2 \cdot 10 \\
1 \cdot 97 \\
2 \cdot 36 \\
2 \cdot 20\end{array}$ & $\begin{array}{l}1.70 \\
1.50 \\
1.15 \\
1.40 \\
1.25 \\
1.40 \\
1.45 \\
1.36 \\
1.51 \\
1.60\end{array}$ & $\begin{array}{l}0.39 \\
0.40 \\
0.52 \\
0.39 \\
0.40 \\
0.39 \\
0.45 \\
0.30 \\
0.50 \\
0.29\end{array}$ & $\begin{array}{r}68 \\
48 \\
71 \\
57 \\
67 \\
57 \\
89 \\
71 \\
83 \\
114\end{array}$ & $\begin{array}{l}39 \\
29 \\
39 \\
33 \\
42 \\
33 \\
31 \\
31 \\
36 \\
27\end{array}$ & $\begin{array}{r}85 \\
84 \\
104 \\
86 \\
88 \\
72 \\
100 \\
80 \\
100 \\
68\end{array}$ & $\begin{array}{l}216 \\
210 \\
199 \\
219 \\
220 \\
183 \\
223 \\
265 \\
201 \\
231\end{array}$ \\
\hline
\end{tabular}

Wd, end-diastolic wall thickness; Ws, end-systolic wall thickness; Dd, end-diastolic left ventricular dimension; Ds, end-systolic left ventricular dimension; BPs, peak systolic blood pressure by Doppler; \% SF, \% shortening fraction; \%WT, \% wall thickening in systole.

and was not significantly different from group 1.

Shortening fraction was increased for group 2, ranging from 27 to 50 per cent (mean $43 \cdot 2 \pm 9 \cdot 2 \%$ ). The youngest infant, with clinical evidence of congestive heart failure and a large left-to-right atrial shunt at catheterisation, had a normal dwelling arterial line or Doppler (case 2). Simultaneous left ventricular peak systolic pressure ranged from 100 to $210 \mathrm{mmHg}$. Using the pressure constant derived from group $1(\mathrm{~K}=217 \mathrm{mmHg})$, estimated left ventricular peak systolic pressure ranged from 123 to $222 \mathrm{mmHg}$. Excellent cor-

Table 2 Aortic stenosis group

\begin{tabular}{|c|c|c|c|c|c|c|c|c|c|c|c|c|c|c|}
\hline \multirow[b]{2}{*}{$\begin{array}{l}\text { Case } \\
\text { no. }\end{array}$} & \multirow[b]{2}{*}{ Age } & \multirow[b]{2}{*}{$\begin{array}{l}\text { Weight } \\
\text { (kg) }\end{array}$} & \multirow[b]{2}{*}{$\begin{array}{l}W d \\
(\mathrm{~cm})\end{array}$} & \multirow[b]{2}{*}{$\begin{array}{l}W s \\
(\mathrm{~cm})\end{array}$} & \multirow[b]{2}{*}{$\begin{array}{l}D d \\
(\mathrm{~cm})\end{array}$} & \multirow[b]{2}{*}{$\begin{array}{l}D s \\
(\mathrm{~cm})\end{array}$} & \multirow[b]{2}{*}{$W s / D s$} & \multirow[b]{2}{*}{$\% \mathbb{W} \boldsymbol{T}$} & \multirow[b]{2}{*}{$\% S F$} & \multirow{2}{*}{$\frac{A o-P_{s}}{m m H_{g}}$} & \multicolumn{2}{|c|}{$L V-P s$} & \multicolumn{2}{|c|}{$\Delta P-P s$} \\
\hline & & & & & & & & & & & $\underset{\text { Cath }}{m m H_{g}}$ & Echo & $\underset{\text { Cath }}{m m H g}$ & Echo \\
\hline $\begin{array}{l}1 \\
2 \\
3 \\
4 \\
5\end{array}$ & $\begin{array}{l}11 \mathrm{mth} \\
2 \mathrm{wk} \\
1 \mathrm{mth} \\
7 \mathrm{mth} \\
8 \mathrm{mth}\end{array}$ & $\begin{array}{r}10 \cdot 4 \\
4.5 \\
4 \cdot 5 \\
7 \cdot 9 \\
8 \cdot 2\end{array}$ & $\begin{array}{l}0.63 \\
0.53 \\
0.51 \\
0.47 \\
0.42\end{array}$ & $\begin{array}{l}1 \cdot 17 \\
0 \cdot 70 \\
0 \cdot 81 \\
1 \cdot 13 \\
0.84\end{array}$ & $\begin{array}{l}2 \cdot 75 \\
1 \cdot 72 \\
1 \cdot 58 \\
2 \cdot 75 \\
2 \cdot 71\end{array}$ & $\begin{array}{l}1.46 \\
1.25 \\
0.79 \\
1.47 \\
1.48\end{array}$ & $\begin{array}{l}0.80 \\
0.56 \\
1.03 \\
0.77 \\
0.57\end{array}$ & $\begin{array}{r}86 \\
32 \\
59 \\
140 \\
100\end{array}$ & $\begin{array}{l}47 \\
27 \\
50 \\
47 \\
45\end{array}$ & $\begin{array}{r}80 \\
55^{\star} \\
100 \\
100 \\
90\end{array}$ & $\begin{array}{l}190 \\
122 \\
210 \\
150 \\
100\end{array}$ & $\begin{array}{l}174 \\
122 \\
222 \\
167 \\
123\end{array}$ & $\begin{array}{r}110 \\
67 \\
110 \\
50 \\
10\end{array}$ & $\begin{array}{r}95 \\
67 \\
122 \\
67 \\
33\end{array}$ \\
\hline
\end{tabular}

Wd, end-diastolic wall thickness; Ws, end-systolic wall thickness; Dd, end-diastolic left ventricular dimension; Ds, end-systolic left ventricular dimension; \%WT, per cent wall thickening in systole; \%SF, per cent shortening fraction; Ao-Ps, peak systolic aortic pressure during cath or ( $\left.{ }^{\star}\right)$ by Doppler ( $\mathrm{mmHg}$ ); LV-Ps, peak systolic left ventricular pressure, in mmHg, during cath and predicted by echo; $\Delta \mathrm{P}-\mathrm{Ps}$, peak systolic pressure difference between $\mathrm{LV}$ and $\mathrm{Ao}$ ( $\mathrm{mmHg}$ ) during catheterisation and predicted by echocardiogram.

shortening fraction of 27 per cent, while an asymptomatic infant with only a $10 \mathrm{~mm}$ peak systolic pressure difference had an abnormal shortening fraction of $\mathbf{4 5}$ per cent.

Peak systolic aortic pressure at catheterisation ranged from 55 to $100 \mathrm{mmHg}$, measured by in- relation $(r=0.94)$ was found between directly measured peak left ventricular pressure and estimated peak pressure (Fig. 2). The peak systolic pressure difference across the aortic valve measured at catheterisation ranged from 10 to $110 \mathrm{mmHg}$, while the pressure difference predicted by echo

Table 3

\begin{tabular}{lclllllll}
\hline & & $W d(\mathrm{~cm})$ & $W s(\mathrm{~cm})$ & $D d(\mathrm{~cm})$ & $D s(\mathrm{~cm})$ & $W s s$ & $\% W T$ & $\% S F$ \\
\hline \multirow{2}{*}{ Group 1 Control } & Mean & 0.33 & 0.58 & 2.18 & 1.43 & 0.40 & 72.5 & 34 \\
& $\pm S D$ & 0.06 & 0.10 & 0.25 & 0.16 & 0.07 & 19.0 & 4.9 \\
\multirow{2}{*}{ Group 2 Aortic stenosis } & Mean & 0.51 & 0.93 & 2.30 & 1.29 & 0.75 & 83.4 & 43.2 \\
& $\pm S D$ & 0.08 & 0.21 & 0.60 & 0.30 & 0.19 & 41.0 & 0.2 \\
& $\mathrm{p}$ & $<0.01$ & $<0.01$ & $>0.5$ & $>0.2$ & $<0.01$ & $>0.4$ & $<0.05$ \\
\hline
\end{tabular}

p value compares group 1 and group 2; SD, standard deviation. Other abbreviations as in Table 1. 
ranged from 33 to $122 \mathrm{mmHg}$. Again, excellent correlation ( $r=0.95)$ was noted (Fig. 3$)$.

\section{Discussion}

Non-invasive assessment of the degree of aortic stenosis has been generally unreliable. While the scalar electrocardiogram may indicate increased left ventricular forces as well as ST segment depression and $T$ wave inversion in the paediatric patient with critical aortic stenosis, a normal resting electrocardiogram may be found in children with a significant peak systolic pressure difference, and show minimal change despite progressive obstruction. ${ }^{6-8}$ While some investigators report the addition of stress electrocardiography and vectorcardiography aided in the detection of moderately severe aortic stenosis, other studies have been less

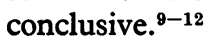

Single crystal echocardiographic determination of left ventricular dimensions has afforded a reliable and reproducible technique in assessing the degree of left ventricular pressure resulting from valvar obstruction in children and adults. Johnson et al. initially used shortening fraction as a predictor of the severity of aortic stenosis. ${ }^{13}$ In the present series, the shortening fraction, while abnormal for group 2 as a whole, was not as discriminating a predictor of severity of obstruction in these infants as has been reported in older children.

As noted by Bennett $e t$ al. and re-emphasised by Glanz et al., derivation of the wall stress constant

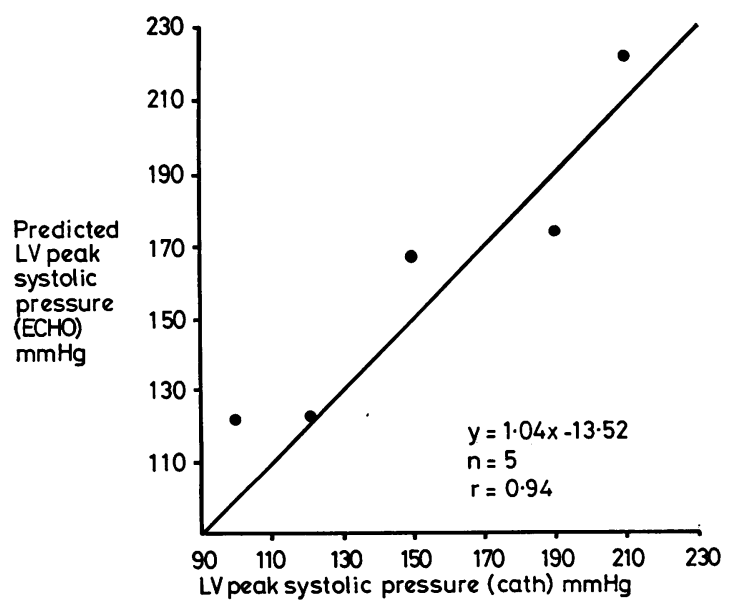

Fig. 2 Comparison of left ventricular ( $L V)$ peak systolic pressure obtained at cardiac catheterisation (cath) with that estimated from echocardiographic data (echo) in five infants with aortic stenosis. Excellent correlation $(r=0.94)$ is noted.

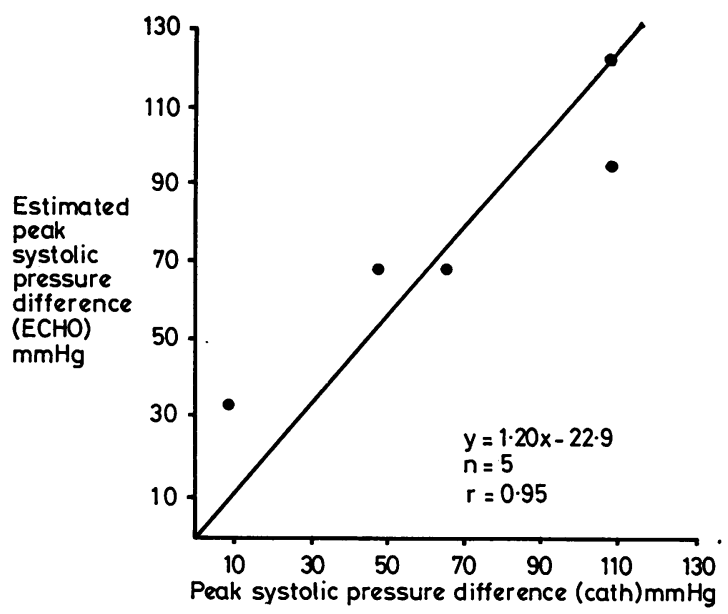

Fig. 3 Comparison of peak systolic pressure difference obtained at cardiac catheterisation (cath) with that estimated from echocardiographic data (echo) in five infants with aortic stenosis. Excellent correlation $(r=0.94)$ is noted.

is based on the observation that left ventricular wall mass will proportionately increase in response to a pressure load until wall stress is normalised, and that systolic stress measurements are more sensitive than diastolic measurements in detecting hypertrophy. For these observations to remain valid, ventricular function must remain normal. In Bennett's adult series, when congestive heart failure was present, severity of obstruction could not be accurately predicted. In Blackwood's group of children, those with myocardial failure were excluded from the study.

Two infants in the present series were felt to be in congestive heart failure. In case 2, while the shortening fraction was not increased and did not suggest significant obstruction, the echo measurement of relative wall thickness indicated severe valvular stenosis. In case 3, both shortening fraction and peak predicted pressure indicated severe obstruction.

One can postulate that the reliability of the wall stress index in these two infants is dependent upon the reduction of left ventricular preload by left atrial dilatation and subsequent left-to-right atrial shunt through the foramen ovale. This allows left ventricular function to remain on the ascending limb or peak of the length-tension curve. Thus, as long as there is a "blow-off" for the volume presented to the left ventricle, ventricular dynamics and cardiac output can be maintained and the index is valid. If a left-to-right atrial shunt is not present, or if the resulting combined pressure load 
to the left ventricle and volume load to the right ventricle exceeds the oxygen demands of the myocardium, caution should be exercised in applying the wall stress index, since cardiac dilatation would lead to underestimation of peak left ventricular systolic pressure.

In summary, these data indicate that the echocardiographic determination of relative wall thickness in infancy allows the most accurate prediction of peak left ventricular pressure and peak systolic pressure differences across an obstructed valve. In patients with aortic stenosis, the technique is ideally suited as a screening device and for serial assessment of increasing pressure difference with age. It should prove useful in selecting a suitable time for cardiac catheterisation and in follow-up management of these patients.

\section{References}

1 Bennett DH, Evans DW, Raj MVJ. Echocardiographic left ventricular dimensions in pressure and volume overload: their use in assessing aortic stenosis. Br Heart f 1975; 37: 971-7.

2 Glanz S, Hellenbrand WE, Berman MA, Talner N. Echocardiographic assessment of the severity of aortic stenosis in children and adolescents. $A m \mathcal{F}$ Cardiol 1976; 38: 620-5.

3 Blackwood RA, Bloom KR, Williams CN. Aortic stenosis in children: experience with echocardiographic prediction of severity. Circulation 1978; 57: 263-8.

4 Gewitz MH, Werner JC, Kleinman CS, Hellenbrand WL, Talner N. Role of echocardiography in aortic stenosis: pre- and postoperative studies. Am f Cardiol $1979 ; 43$ : 67-73.
5 Bass JL, Einzig S, Hong CY, Moller JH. Echocardiographic screening to assess the severity of congenital aortic valve stenosis in children. $A m \mathcal{F}$ Cardiol 1979; 44: 82-7.

6 Ongley PA, Nadas AS, Paul MH, et al. Aortic stenosis in infants and children. Pediatrics 1958; 21: 207-20.

7 Reynolds JL, Nadas AS, Rudolph AM, Gross RE. Critical congenital aortic stenosis with minimal electrocardiographic changes. $N$ Engl f Med 1960; 262: 276-82.

8 Friedman WF, Modlinger J, Morgan JR. Serial hemodynamic observations in asymptomatic children with valvular aortic stenosis. Circulation 1971; 43: 91-8.

9 Halloran KH. The telemetered exercise electrocardiogram in congenital aortic stenosis. Pediatrics 1971; 47: 31-9.

10 Hugenholtz PG, Lees MM, Nadas AS. The scalar electrocardiogram, vectorcardiogram and exercise electrocardiogram in the assessment of congenital aortic stenosis. Circulation 1962; 26: 79-91.

11 Gamboa R, Hugenholtz PG, Nadas AS. Comparison of electrocardiograms and vectorcardiograms in congenital aortic stenosis. Br Heart $\mathcal{f}$ 1965; 27: 344-54.

12 Reeve R, Kawamata K, Selzer A. Reliability of vectorcardiography in assessing the severity of aortic stenosis. Circulation 1966; 34: 92-9.

13 Johnson GL, Meyer RA, Schwartz DC, Korf hagen J, Kaplan S. Left ventricular function by echocardiography in children with fixed aortic stenosis. Am $\mathcal{F}$ Cardiol 1976; 38: 611-9.

Requests for reprints to $\mathrm{Dr}$ Joel I Brenner, Division of Pediatric Cardiology, Room 5-1200, University of Maryland Hospital, 22 South Greene Street, Baltimore, Maryland 21201, USA. 